\title{
O REFLEXO DAS INTERVENÇÕES URBANAS NA PSIQUE DOS HABITANTES DA CIDADE - A RELAÇÃO ENTRE URBANISMO E PSICOLOGIA SEGUNDO CARL GUSTAV JUNG
}

\author{
Mario Elian ${ }^{1}$
}

\author{
Camilo Michalka²
}

\begin{abstract}
RESUMO
É alentador constatar como, nas últimas décadas, em ritmo progressivo, o uso da visão sistêmica dentro de uma abordagem interdisciplinar e transdisciplinar tem se intensificado em todos os campos dos saberes acadêmicos. Nas interconexões entre a cidade e a psicologia avanços crescentes tem consolidado a certeza de que é impossível desassociar o fenômeno urbano do fenômeno humano. $\mathrm{O}$ psiquiatra e psicoterapeuta suíço Carl Gustav Jung, considerado o fundador da psicologia analítica identificou a mandala como expressão da psique do ser humano, considerando-a como símbolo do inconsciente coletivo. Constata-se que, ao longo da história, o arquétipo da mandala tem estado presente na planta de edifícios e no desenho urbano. É neste sentido e direção que o presente artigo se alinha, ao enfocar a interconectividade entre psicologia, psique e cidade, e o fenômeno urbano com o fenômeno humano. Se o homem é o criador da cidade, o fenômeno humano é indissociável do fenômeno urbano. Conclui-se que é de importância fundamental considerar o fenômeno humano nas intervenções urbanas. Isso permite que seja garantida a manutenção dos laços de identidade do cidadão com a sua cidade, o que leva ao sentimento de pertencimento. Isso é fundamental no processo de coesão social, evitando que a cidade se transforme em "terra de ninguém", sem defensores de sua integridade, funcionamento e beleza.
\end{abstract}

Palavras-Chave: Cidade, Psique, Psicologia Analítica, identidade

\footnotetext{
${ }^{1}$ Arquiteto pela Universidade Federal do Rio de Janeiro, Psicólogo pela Universidade Santa Úrsula RJ, Especialista em Engenharia Urbana pela Escola Politécnica da Universidade Federal do Rio de Janeiro (PEU/Poli/UFRJ). Mestrando em Engenharia Urbana pela Escola Politécnica da Universidade Federal do Rio de Janeiro (PEU/Poli/UFRJ).E-mail: mario.elian1@gmail.com.

${ }^{2}$ Engenheiro Civil, Mestre em Engenharia Civil pela COPPE/ UFRJ, Doktor Ingenieur pela Universität Stuttgart (Alemanha) e bolsista de Pós-doutorado na Alemanha pelo CNPQ, Programa Ciências sem Fronteiras. É professor associado da Escola Politécnica da Universidade Federal do Rio de Janeiro (Poli/UFRJ), membro efetivo do Programa de Mestrado Profissional em Engenharia Urbana (PEU/Poli/UFRJ) e coordenador do Laboratório de Estudos Estratégicos e Ambientais (www.leeamb.poli.ufrj.br). E-mail: michalka@poli.ufrj.br .
} 


\title{
GLARE OF URBAN INTERVENTION IN PSYCHE OF CITY PEOPLE - THE RELATIONSHIP BETWEEN URBAN AND PSYCHOLOGY SECOND CARL GUSTAV JUNG
}

\begin{abstract}
SUMMARY
It is encouraging to see, as in recent decades, in a progressive pace, systemic vision within an interdisciplinary and transdisciplinary approach has intensified in all fields of academic knowledge. In the interconnections between the city and the psychology, increasing advances have consolidated certain that it is impossible to disassociate the urban phenomenon of the human phenomenon. The Swiss psychiatrist and psychotherapist Carl Gustav Jung, the founder of analytical psychology identified the mandala as an expression of the psyche of the human being, considering it as a symbol of the collective unconscious. It appears that, throughout history, it has been present in buildings plans and urban design. In this sense and the direction that this article aligns by focusing on the interconnectedness among psychology, psyche and city, and the urban phenomenon and the human phenomenon. If man is the creator of the city, the human phenomenon is inseparable from urban phenomenon. We conclude that is of fundamental importance to consider the human phenomenon in urban interventions. This allows to guarantee the maintenance of citizen's identify to their city, which leads to the feeling of belonging. This is fundamental in the process of social cohesion, preventing the city from turning into "no man's land", without defenders of their integrity, function and beauty.
\end{abstract}

Keywords: City, Psyche, Analytical Psychology, Identity

\section{REFLEJO DE INTERVENCIÓN URBANA EN PSIQUE DE LA GENTE DE LA CIUDAD - LA RELACIÓN ENTRE ZONAS URBANAS Y SEGUNDO PSICOLOGÍA CARL GUSTAV JUNG}

\section{RESUMEN}

Es alentador observar como, en las últimas décadas, en ritmo progressivo, el uso de la visión sistémica dentro de um enfoque interdisciplinar y transdisciplinar se há intensificado en todos los campos del conocimiento académico. En las interconexiones entre la ciudad y la psicología avances han consolidado la certeza de que es imposible disociar el fenómeno urbano del fenómeno humano. El psiquiatra suizo y psicoterapeuta Carl Gustav Jung, el fundador de la psicologia analítica indentificó la mandala como expresíon de la psique del ser humano, considerandola como símbolo de inconsciente coletivo. Se constata que a lo largo de la historia, el arquetipo de la mandala, há estado presente en la planta de los edifícios y en diseño urbano. Es en este sentido y dirección que el presente artículo se alínea, centrándose em la interrelación entre la psicología, psique y la ciudad, y el fenómeno urbano. Si el hombre es el creador de la ciudad, el fenómeno humano es inseparable del fenómeno urbano. Llegamos a la conclusión que es de fundamental importancia considerar el fenómeno humano en las intervenciones urbanas. Esto permite que sea garantida la mantencíon de los lazos de identidad del ciudadano com su ciudad, lo que conduce a la sensación de 


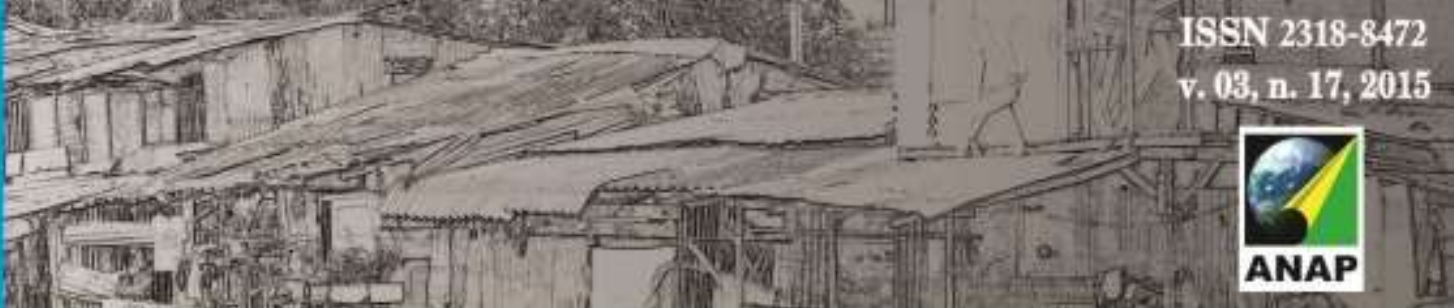

\section{Revista Nacional de}

Gerenciamento de Cidades

pertenecimiento, fundamental en el processo de la cohesión social, evitando que la ciudad se convierta em "tierra de nadie", sin defensores de su integridad, funcionalidad y beleza.

palabras-clave: Ciudad, Psique, Psicología Analítica, Identidad

\section{INTRODUÇÃO}

Joseph Rykwert confirmava por meio de pesquisas profundas e abrangentes de caráter arqueológico e antropológico, que a fundação e a forma das cidades antigas do Ocidente "não eram fundamentadas em princípios funcionais ou utilitários, mas numa visão cosmológica presente, como um fenômeno universal entre todos os povos". (RYKWERT, 2006, pg.33)

O historiador britânico Toyinbee aborda 0 fato de que o homem de Neandertal praticava cerimônias fúnebres, e fundava a mais primitiva cidade, a Necrópole, não tendo, portanto esta qualquer fim utilitarista. (TOYINBEE, 1987)

Hall (1996), em seu livro "A dimensão Oculta", sintetiza em seu texto:

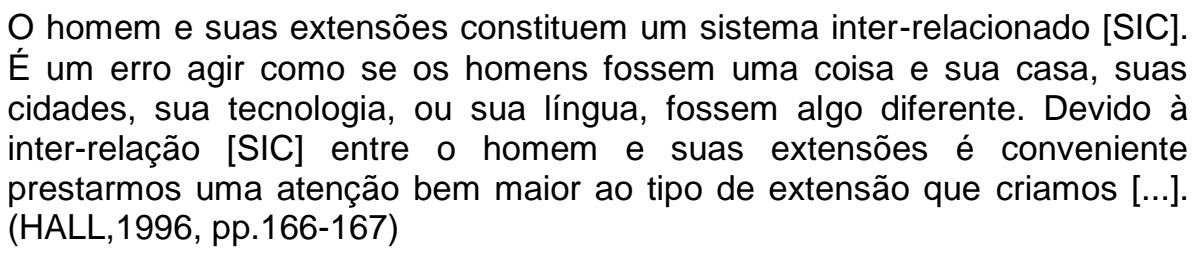

O mundo tridimensional, com formas, cores, geometrias, volumetrias, influencia diretamente o ser humano. (ARNHEIN, 2005)

Para Jung, a percepção, a nível consciente, do mundo material é a ponta de um iceberg, que se expande nas profundezas de um inconsciente fundamental e dinâmico, que se diferencia do inconsciente pessoal, este, inconsciente exclusivamente repositório da experiência pessoal reprimida e infantil. A esse inconsciente fundamental ele denominou inconsciente coletivo, que operaria 


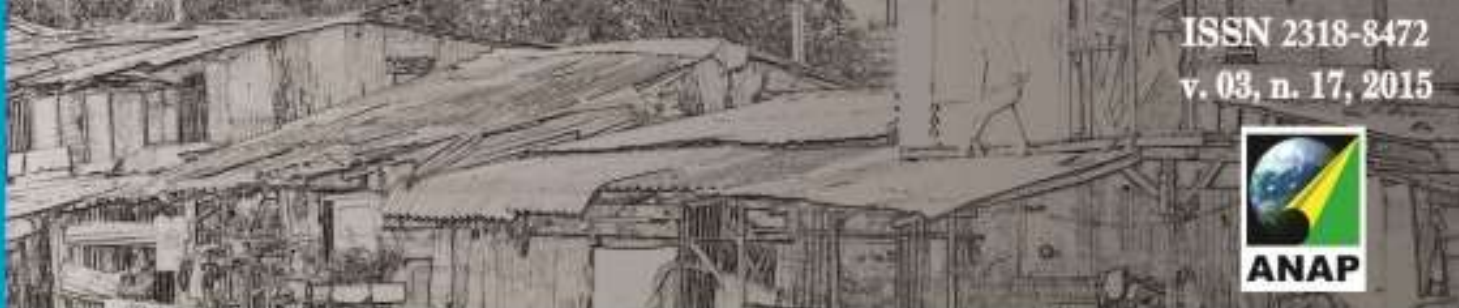

\section{Revista Nacional de}

Gerenciamento de Cidades

independentemente do nível percepcional consciente devido a sua estrutura herdada da formação do cérebro através das eras (Figura 1).

Figura 1: As camadas do inconsciente segundo Jung

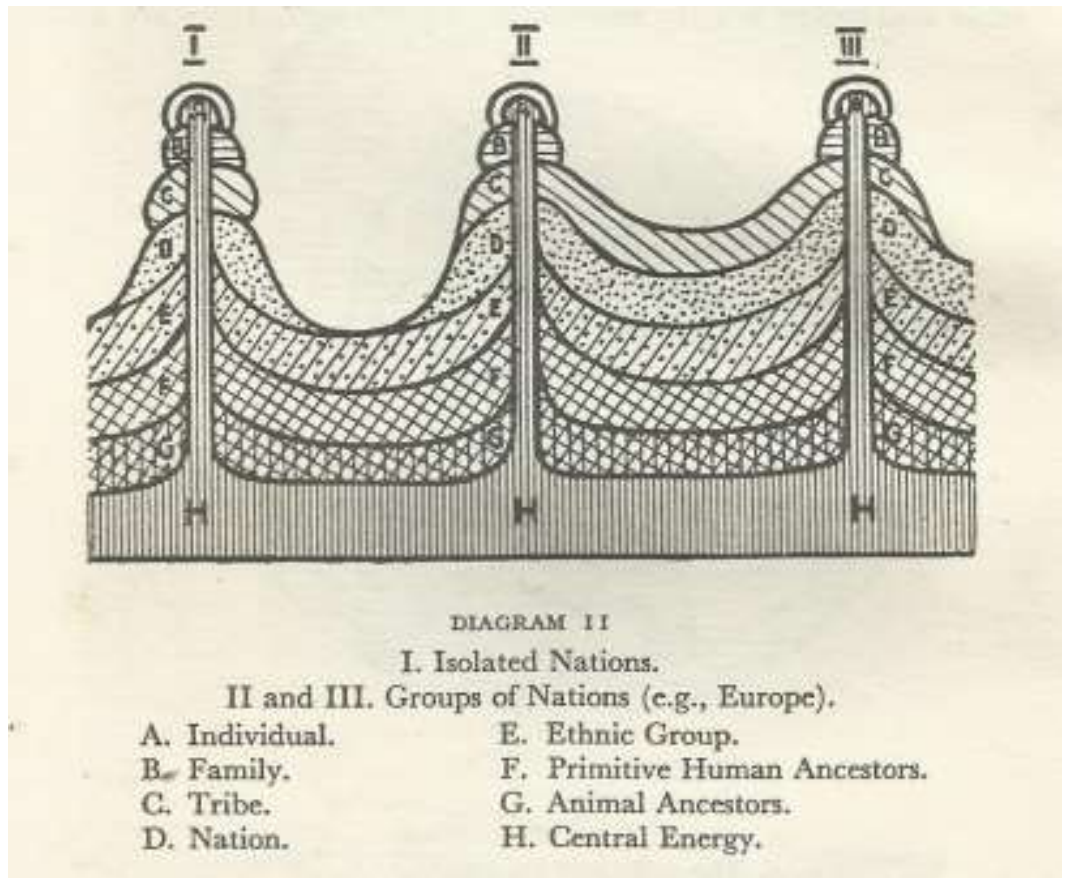

Fonte: Adaptado de Jacobi (1976, p 34)

Para Jung, o inconsciente coletivo é potencialmente criativo, e funciona em prol do desenvolvimento do indivíduo e da espécie. O inconsciente coletivo é constituído de arquétipos, fatores irrepresentáveis e invisíveis que agem sobre o inconsciente do ser humano, que se evidenciam somente através de suas manifestações, nos sonhos, mitologias, contos de fadas, folclores, símbolos religiosos etc..

Para o psiquiatra e psicoterapeuta suíço Carl Gustav Jung (2008) a psique do ser humano poderia ser representada esquematicamente por uma esfera, na qual uma pequena área de sua superfície conteria a consciência e, no centro e núcleo dessa esfera, o verdadeiro centro ordenador da psique, que Jung denominou "Self", considerado em sua psicologia como o arquétipo central (Figura 2). 


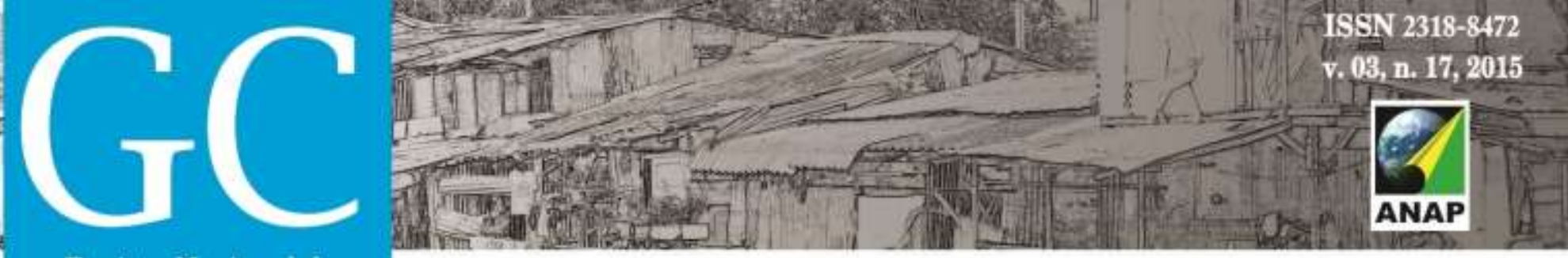

\section{Revista Nacional de}

Gerenciamento de Cidades

Jung identificou a mandala, palavra sânscrita que significa "circulo mágico", muito recorrente nas tradições filosóficas e religiosas do antigo Tibet. Ela é uma figura geométrica em que o círculo está circunscrito em um quadrado ou o quadrado em um círculo, como o símbolo desse arquétipo central. Para Jung ela é a expressão da psique do ser humano e do "Self"; o verdadeiro centro ordenador da psique.

Figura 2: Representação da psique

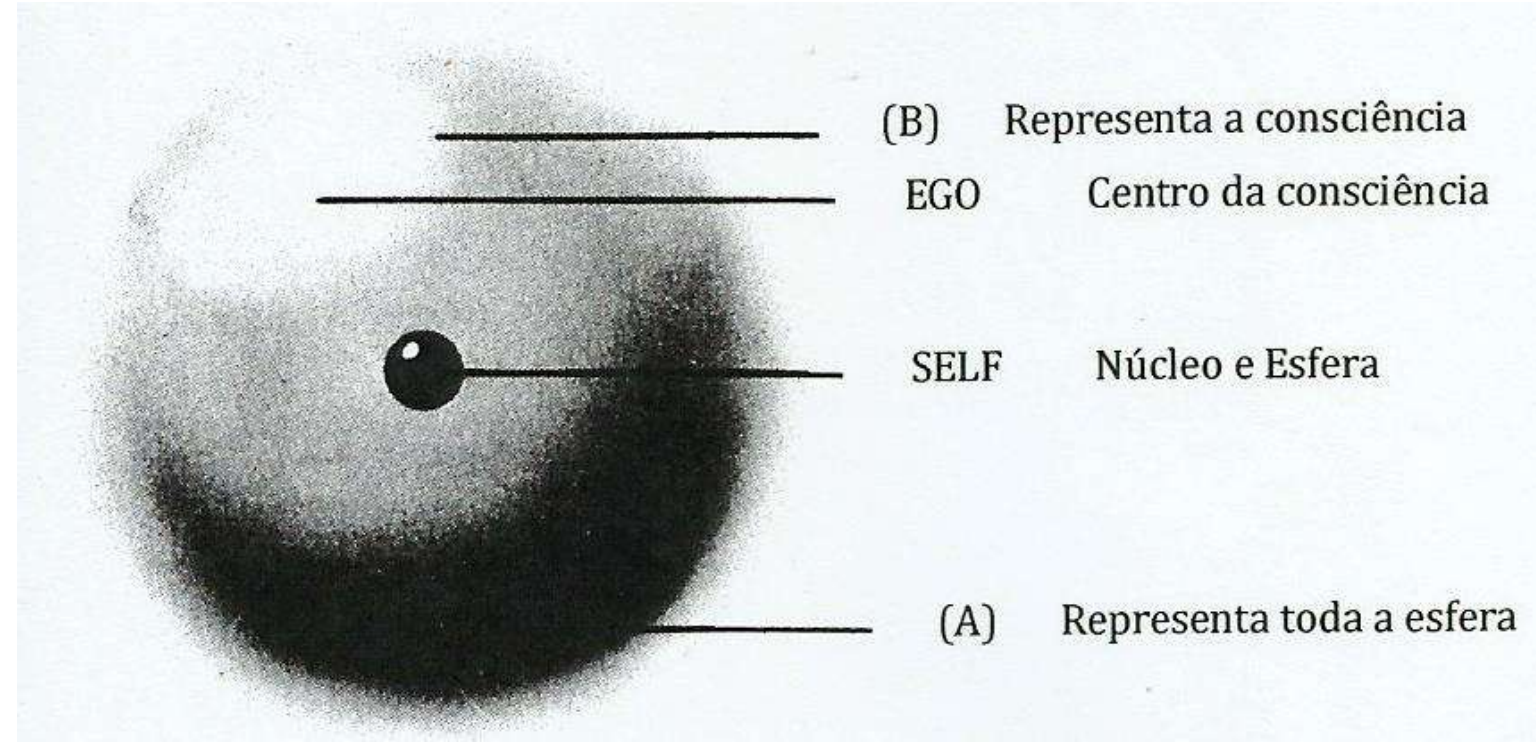

Fonte: Adaptado de JUNG (2008)

As mandalas surgem espontaneamente em sonhos, e nas mais variadas formas de expressões culturais e religiosas no mundo inteiro. 


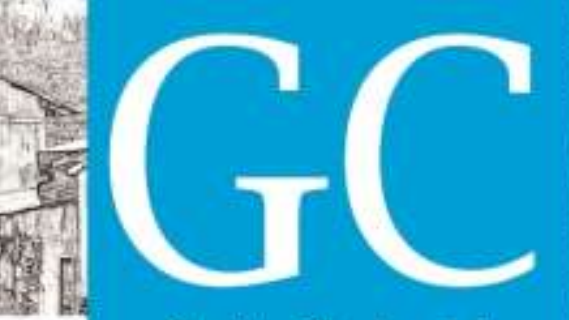

Revista Nacional de

Gerenciamento de Cidades

Uma das principais colaboradoras de Carl G Jung, Marie Louise Von Franz afirma que a mandala representa um papel importante na planta de edifícios seculares e religiosos desde as mais remotas eras, e numa proporção equivalente, na urbanização clássica, medieval e moderna, que muitas vezes passa despercebida (Figuras 4, 5 e 7) e assinala também que, plantas em forma de mandala, podem ser identificadas também em cidades contemporâneas. (JUNG, 2008).

Figura 4: Planta urbanística de Washington

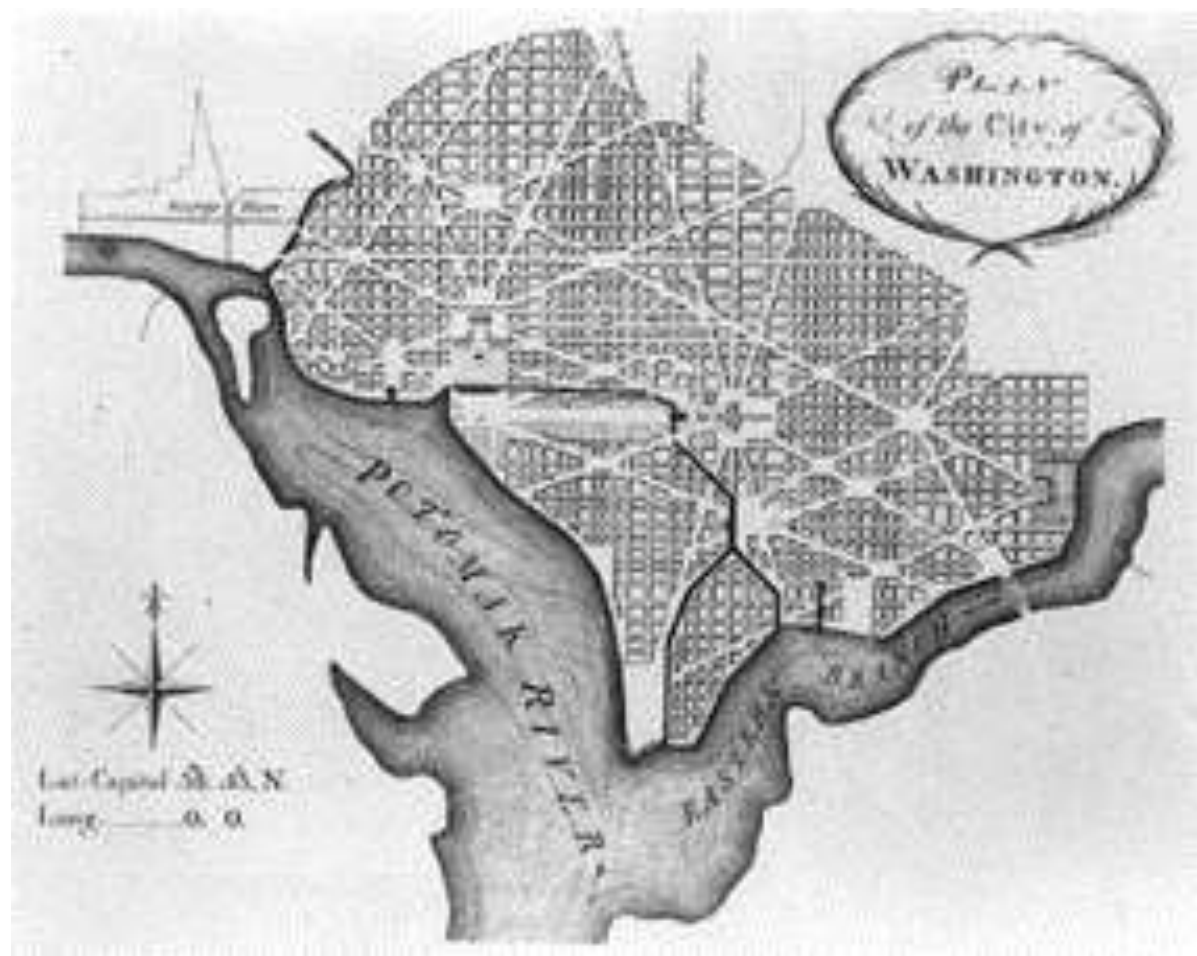

Fonte: http://www.bifurcaciones.cl/001/colerese/Plan\%20of\%20the\%20City\%20of\%20Washington, \%20L'Enfant\%20(1792).jpg._Acesso em: 27 maio 2015. 


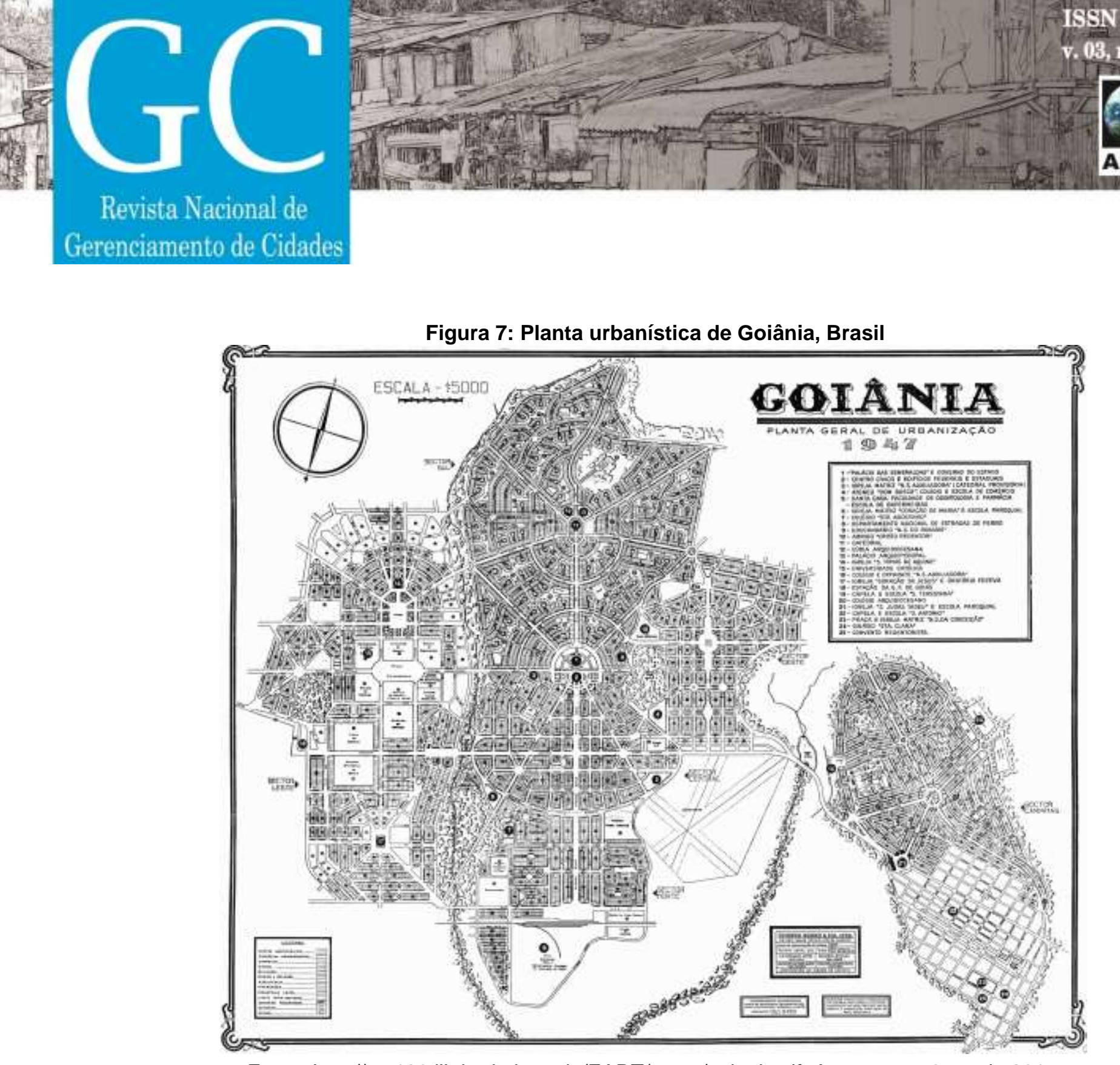

Fonte: http://vm136.lib.berkeley.edu/EART/maps/goianix.gif__Acesso em: 27 maio 2015.

Para Jung, os fenômenos, repercutem na psique humana muito além do que apreendem os sentidos e todo o campo da consciência. Afirma que todas as manifestações do fenômeno humano, que em sua totalidade passam pela psique, são inconscientemente influenciadas pelos arquétipos do inconsciente coletivo, comum a toda humanidade.

\section{A CIDADE OCULTA}

Sob a luz da denominada Psicologia Profunda ou Psicologia Analítica de Carl Gustav Jung, pode-se ter uma dimensão mais clara da gravidade que representa para a população de uma cidade uma intervenção urbana que não leve 
em consideração a preservação de seu patrimônio cultural, ambiental e afetivo, fatores primordiais para a garantia da qualidade de vida de seus cidadãos. As marcas profundas deixadas por intervenções que não levem em consideração os fatores supracitados impedem a possibilidade da manutenção da identidade dos seus habitantes com sua cidade, numa profundidade que transpõe o seu nível consciente. Essa cisão só pode ser cicatrizada com o resgate da identidade, através de uma política pública urbana de preservação e reconstituição de elementos da memória perdidas da cidade.

As cidades são intrinsicamente dinâmicas e precisam se desenvolver. Entretanto se não houver diretrizes claras e precisas que orientem modificações na cidade, que evitem a derrocada do sentimento de pertencimento do cidadão a ela, essa desidentificação será indefectivelmente geradora de caos urbano. Essas diretrizes necessitam, obrigatoriamente, preservar elementos urbanos e seus edifícios que representem valores de vida e da memória, incalculáveis como legado histórico e afetivo do(s) indivíduo(s). Esse objetivo desejável só poderá ser atingido quando, através de leis específicas, a participação efetiva da sociedade civil possa ser assegurada e respeitada.

$\mathrm{Na}$ origem das cidades, desde a Antiguidade, podem-se identificar raízes profundas do fenômeno humano que açambarcam conteúdos do inconsciente coletivo.

Rykwert (2006) demonstra que cidades etrusco-romanas eram originadas por traçados dos agrimensores, a partir de uma cruz, um símbolo arquetípico do inconsciente coletivo. A perenidade dos arquétipos é demonstrada, quando é constatado que cidades modernas também se originam desse mesmo arquétipo, como é o caso de Brasília, de Lúcio Costa. 


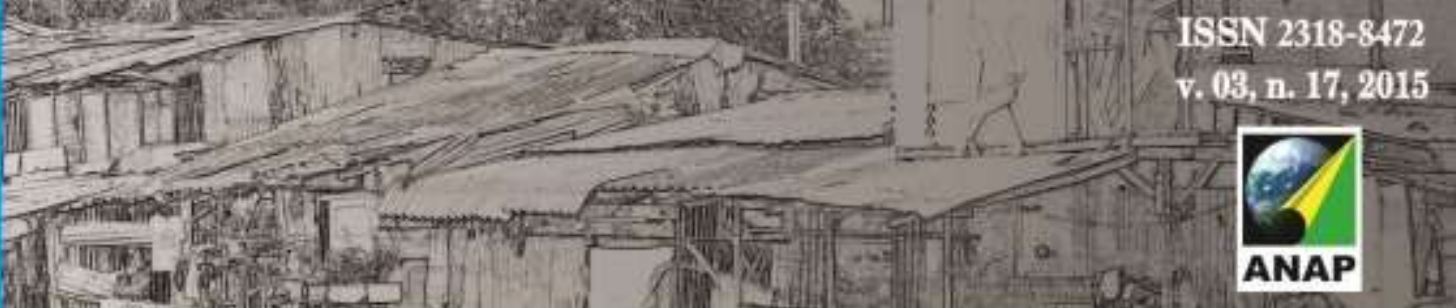

\section{Revista Nacional de}

Gerenciamento de Cidades

Figura 8: Projeto de Brasília, Lúcio Costa
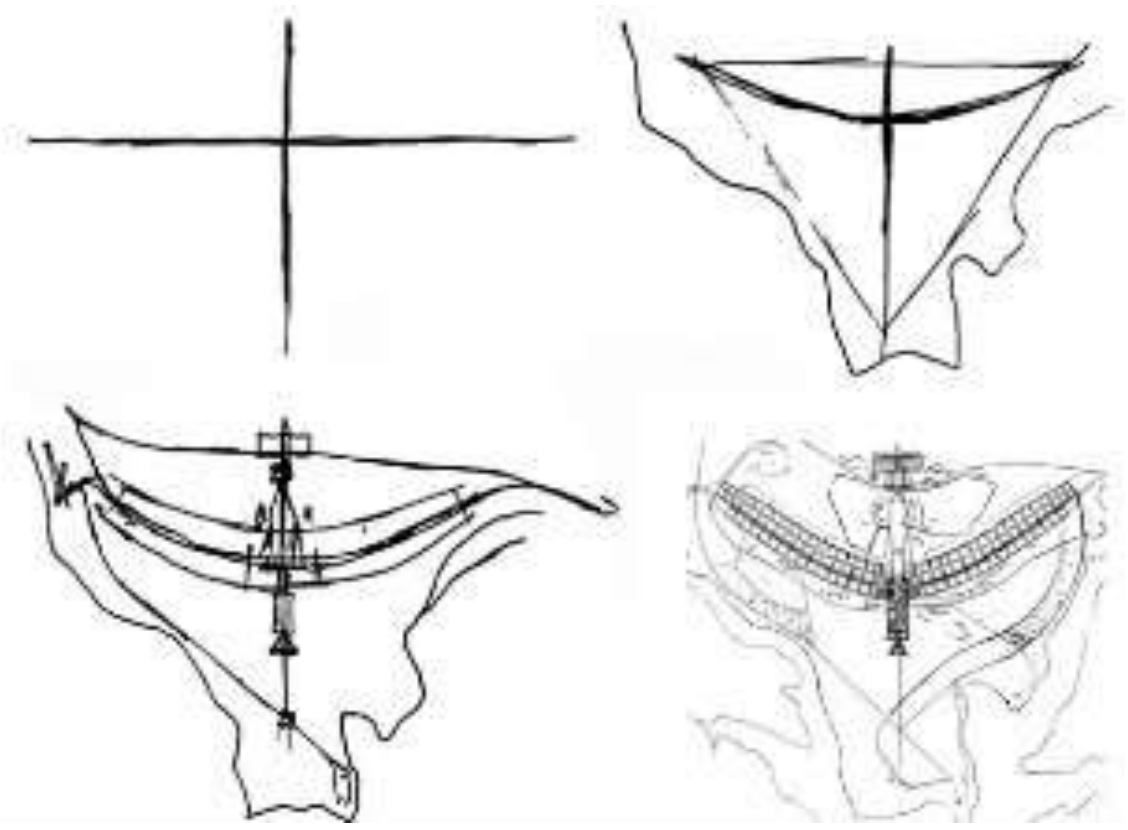

Fonte: http://epocanegocios.globo.com/Revista/Epocanegocios2/foto/0,,40221733,00.jpg.Acesso em: 27 maio 2015.

Ele apontada arquétipos do inconsciente coletivo como elementos geradores de formas da cidade, e não princípios racionais, que eram subsequentes, após as origens das mesmas. Os estudos de caráter antropológico e arqueológico do autor mostram que a fundação e a forma das cidades antigas do ocidente não eram baseadas em princípios funcionais ou utilitários, mas numa visão cosmológica, que estava presente como fenômeno universal entre todos os povos. Os princípios racionais eram desenvolvimentos subsequentes após a origem das mesmas. Ele estabeleceu analogias marcantes entre civilizações mediterrâneas no Oriente e em tribos da África e das Américas, no que dizia respeito à relação entre assentamentos e o cosmos. Essas analogias indicavam:

[...] a existência de um modelo fundamental do pensamento humano enraizado na estrutura biológica do homem, e cuja essência estaria na reconciliação do indivíduo com seu próprio destino." (RYKWERT, 2006, p 24) 
Tanto para Rykwert, como para Jung, as estruturas físicas e estéticas da cidade moderna estariam desvinculadas dos significados simbólicos originais, que foram metamorfoseados ou perdidos, com a crescente complexidade física e social das mesmas. (RYKWERT, 2006)

Rykwert propôs a recuperação do elemento inconsciente no homem e seus arquétipos, como uma maneira de viabilizar o espaço como habitat. Ele sempre teve uma postura crítica aos urbanistas que consideram a cidade exclusivamente pela perspectiva da economia, da higiene, dos problemas de tráfego ou dos serviços. Afirmava que os tecidos urbanos deveriam permitir àqueles que o habitam, a qualquer momento de sua história, ter uma leitura clara de sua cidade, no sentido de poder compreender suas camadas superpostas, e ter sempre condição de situar-se em relação aos que junto com ele, nela convivem, e a todos os seus antepassados. Fundamentando-se em diversos autores da era clássica, constatava que a fundação das cidades etrusco-romanas, por exemplo, não eram fundadas por princípios determinantes racionais, tais como estratégias de defesa, controle de rotas de comércio, ou qualquer outro motivo econômico, mas por determinantes simbólico ritualísticos, tais como exame de augúrios, que incluíam a trajetória de pássaros voando, o comportamento de certos animais, exame de vísceras de espécies desse reino, o ribombar de trovões e uma grande diversidade de sinais vindos da natureza que eram decifrados "como mensagens divinas que referendavam ou não a escolha dos homens." (RICKWERT, 2006, pg.34).

Em sua abrangente pesquisa, vai muito além do exemplo etrusco-romano e identifica similitudes em fundações de cidades em várias outras sociedades primitivas. Carl Gustav Jung já havia identificado a ocorrência dos arquétipos do inconsciente coletivo nas culturas e religiões das principais civilizações conhecidas na Terra. 


\section{CONCLUSÃO}

Para que se tenha uma cidade humana, reflexo dos seus habitantes e que com ela se identifiquem, o fenômeno humano necessita ser sempre considerado em qualquer intervenção urbana. É preciso que uma intervenção garanta a criação e manutenção dos laços de identidade do cidadão com sua cidade, através da preservação de seu patrimônio histórico, cultural, ambiental e afetivo. Também a reconstituição de elementos da memória afetiva dos habitantes de uma cidade reatam os laços do sentimento de pertencimento, indispensáveis para o fortalecimento da coesão social. Nesse contexto se torna fundamental a participação dos cidadãos na no processo de tomada de decisão na construção de sua cidade, ou seja, de seu destino. Para isso se torna necessário complementar as leis de participação do indivíduo no processo de tomada de decisão urbana, como abordado por Araújo e Michalka (2014).

Sob a luz da Psicologia analítica de Carl Gustav Jung, pode-se vislumbrar com mais clareza as razões pelas quais as grandes cidades brasileiras tem se transformado em "terra de ninguém", sem defensores de sua integridade, funcionamento e beleza. Isso tem ocorrido também nas cidades que crescem em ritmo acelerado.

Conclui-se que, baseado no que coloca Jung, uma cidade que não leve em consideração as estratificações psíquicas, dos seus níveis mais básicos aos mais profundos, do concreto sensorial, voltando até àquelas formadas pela história da própria humanidade, inscritos no seu inconsciente coletivo, estará fadada a criar cisões profundas e irreversíveis entre seus habitantes como também com os espaços onde vivem. 


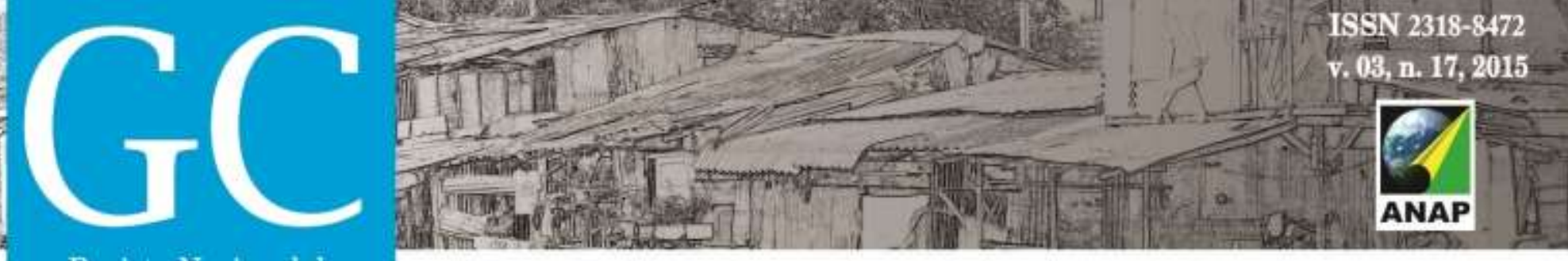

\section{Revista Nacional de}

Gerenciamento de Cidades

\section{REFERÊNCIAS}

ARAÚJO, Andréa A; MICHALKA, Camilo. Regularizar a Participação Popular Pode Ser a Saída para a Atual Crise da Democracia Representativa. Caminhos para a sustentabilidade urbana / Sandra Medina Benini e Gilda Collet Bruna (Org.) - Tupã: ANAP, 2014.

ARNHEIN, Rudolf. Arte e Percepção Visual. Ed. Universal de São Paulo: 2005.

HALL, Edward T. A dimensão Oculta. Ed. Martins Fontes: 1996.

JACOBI, Jolande. The Psychology of C.G. Jung. Ed. Yale University Pres: 1976.

JUNG, C.G. O homem e seus Símbolos. Ed. SNEL, RJ, Nova Fronteira, 2008.

PIERI, Paolo Francesco. Dicionário Junguiano. Ed. Paulus: 2002.

RYKWERT, Joseph. A ideia de Cidade. Ed. Perspectiva: 2006.

TOYNBEE, Arnold J. A humanidade e a Mãe Terra. Ed. Guanabara: 1987.

VON FRANZ, Marie Louise. O processo de Individuação. Em O homem e seus Símbolos. JUNG, C.G (Org.). Ed. SNEL, RJ, Nova Fronteira, 2008.

XAVIER, César Rey. A Permuta dos Sábios. Ed. Annablume: 2003. 